\title{
Extensão comunitária com visão educativa: Uma relação entre a teoria e a prática social
}

\section{Community extension with educational vision: A relationship between theory and social practice}

DOI: $10.46814 /$ lajdv2n6-024

Recebimento dos originais: 01/09/2020

Aceitação para publicação: 30/10/2020

\section{Claudio Luiz Orço}

Doutor em Educação pela USFC. Professor e Diretor Acadêmico da Unoesc Xanxerê, situada na rua Dirceu Giordani 696, Bairro Jardim Tarumã, Xanxerê/SC, CEP 89820-000.

E-mail: claudio.orco@unoesc.edu.br

\section{Elizandra IOP}

Mestre em Educação pela Universidade do Contestado UnC em convênio com a Universidade estadual de Campinas - Unicamp, Professora da Unoesc Xanxerê, situada na rua Dirceu Giordani 696, Bairro Jardim Tarumã, Xanxerê/SC, CEP 89820-000.

E-mail: elizandra.iop@unoesc.edu.br

\section{Betania de Marco}

Especialista em Gestão Universitária pela Univalli e Consultoria e Auditoria de Gestão pela Unoesc Xanxerê. Professora da Unoesc Xanxerê, situada na rua Dirceu Giordani 696, Bairro Jardim Tarumã,

Xanxerê/SC, CEP 89820-000.

E-mail: betania.demarco@unoesc.edu.br

\section{Rosiclei Brandalise de Vicentini}

Especialista em Educação Infantil e Alfabetização em Séries Iniciais do Ensino Fundamental pela Unoesc Xanxerê. Assessora da Diretoria Acadêmica da Unoesc Xanxerê, situada na rua Dirceu

Giordani 696, Bairro Jardim Tarumã, Xanxerê/SC, CEP 89820-000.

E-mail: rosiclei.vicentini@unoesc.edu.br

\section{Bruna Macedo Bruchez}

Graduada em Engenharia Bioenergética pela Unoesc Xanxerê. Assessora da Diretoria Acadêmica situada na rua Dirceu Giordani 696, Bairro Jardim Tarumã, Xanxerê/SC, CEP 89820-000.

E-mail: bruna.bruchez@unoesc.edu.br

\section{RESUMO}

O presente artigo é resultado de uma parceria entre a Diretoria Acadêmica, o Serviço de Apoio ao Estudante, as Coordenações de Cursos de Graduação e acadêmicos da Universidade do Oeste de Santa Catarina - Unoesc Xanxerê/SC, contemplados com bolsas de estudos vinculados ao Artigo 170 da Constituição Estadual de Santa Catarina. A proposta desenvolvida visa o atendimento do compromisso do acadêmico em contribuir com a comunidade com trabalho de cunho educativo vinculado ao seu curso de formação acadêmica. A Unoesc Xanxerê/SC, desde 2012 vem implementando projetos voltados para as áreas de atuação dos Cursos, envolvendo anualmente cerca de 750 bolsistas beneficiados. Em 2013, os projetos, tornaram-se um Programa Extensão Universitária, envolvendo os acadêmicos bolsistas e atendendo anualmente mais de 5.000 pessoas da comunidade local e regional. Assim a Universidade conseguiu colaborar com os bolsistas, 
preparando-os para prestarem serviços comunitários oferecendo uma formação social, na área do ensino, da pesquisa e da extensão, para além do espaço acadêmico, sob a orientação do seu coordenador do Curso. Os recursos financeiros utilizados para viabilizar o Programa, são da própria instituição, promovendo a disseminação do conhecimento, garantia da qualidade de ensino e condições de acesso e permanência dos acadêmicos na Universidade, fortalecendo a indissociabilidade entre o Ensino Pesquisa e Extensão.

Palavras-chaves: Projetos, Extensão comunitária, Universidade.

\begin{abstract}
This article is the result of a partnership between the Academic Board, the Student Support Service, the Undergraduate Course Coordinators and academics of the University of the West of Santa Catarina - Unoesc Xanxerê / SC, awarded scholarships linked to Article 170 of the State Constitution of Santa Catarina. The proposal developed objective to meet the academic commitment to contribute to the community with educational work linked to their academic training course. Since 2012, Unoesc Xanxerê / SC has implemented projects aimed at the areas in which the Courses operate, involving approximately 750 beneficiaries on an annual basis. In 2013, the projects became a University Extension Program, involving scholarship scholars and annually assisting more than 5,000 people from the local and regional community. Thus, the University managed to collaborate with the scholarship, preparing them to provide community services by offering social training, in the area of teaching, research and extension, in addition to the academic space, under the guidance of their Course Coordinator. The financial resources used to make the Program viable come from the institution itself, promoting the dissemination of learning, guaranteeing the quality of teaching and conditions for access and permanence of academics at the University, strengthening the inseparability between Research and Extension Education.
\end{abstract}

Key words: Projects, Community extension, University.

\title{
1 CONSIDERAÇÕES INICIAIS
}

O presente trabalho tem por objetivo discutir o papel da Universidade Comunitária e sua relação com a comunidade externa com destaque para a Universidade do Oeste de Santa Catarina Unoesc Xanxerê, que tem seu foco o desenvolvimento local e regional.

Inicialmente, apresentamos um breve histórico sobre a criação da Unoesc enquanto Universidade Comunitária, que tem sua origem na articulação das lideranças políticas municipais e da sociedade civil que percebiam as necessidades locais e regionais e a falta de qualificação de recursos humanos para atuarem em prol a transformação social e econômico da sociedade em formação. Tal necessidade continua latente no cenário atual, fazendo com que a Unoesc Xanxerê comprometida com a transformação social, se organize e estenda o conhecimento técnico científico para a comunidade por meio de um Programa criado pela Diretoria Acadêmica, o Serviço de Apoio ao Estudante, as Coordenações de Cursos de Graduação e acadêmicos da Universidade do Oeste de Santa Catarina - Unoesc Xanxerê/SC, contemplados com bolsas de estudos vinculados ao Artigo 170 da Constituição Estadual de Santa Catarina. 
Para tanto, o artigo traz a educação como um direito social previsto pela Constituição Federal de 1988 a todo cidadão brasileiro, como um direito fundamental para o desenvolvimento da pessoa humana e para o exercício pleno da cidadania. Em seguida aborda o campo conceitual da Extensão, bem como da Extensão Comunitária articulando-os ao Programa de Extensão Comunitária desenvolvido pela Unoesc Xanxerê como meio de estender o conhecimento técnico científico em prol da comunidade, dessa forma promover o contato de distintas realidades social ao acadêmico ainda durante sua formação universitária.

\section{HISTÓRICO DAS UNIVERSIDADES COMUNITÁRIAS NO ESTADO DE SANTA CATARINA}

O estado de Santa Catarina impulsionou a expansão de uma política de ensino superior no interior do estado por meio das Instituições Isoladas de Ensino Superior e que hoje são Universidades Comunitárias, com a finalidade de promover o desenvolvimento regional que na época estava ameaçado devido a ausência de produção de conhecimento técnico-científico.

Este modelo de ensino superior que se concentra mais ao Sul do país, embora existam instituições dessa natureza em todo país, é em SC e RS que elas apresentam características do modelo comunitário, regulamentadas pela Lei n 12.881, de 12 de dezembro de 2013 (BRASIL, 2013).

As Instituições Comunitárias de Ensino Superior - ICES, atuam desde sua criação entre os anos de 1940 e 1970, dentro de um contexto sociopolítico do Estado desenvolvimentista, mas foi somente na década de 1990 que se consolidaram em sua grande maioria enquanto Universidades. Sua instalação deu-se pela ausência de políticas públicas de interiorização do ensino superior nas regiões mais pobres e distantes da capital do Estado.

As Instituições Comunitárias foram criadas sem a participação do Estado, "[...]como uma iniciativa que não nasce no núcleo do poder público-estatal, mas na sua periferia, como expressão de vozes e vontades que querem se fazer ouvir e participar da construção de um espaço de educação socialmente mais amplo e democrático" (FRANTZ; SILVA, 2002, p.34).

O ambiente político da época dava sinais da emergência pela expansão e interiorização do ensino superior no estado de SC, ocorrendo uma mobilização da sociedade civil à implantação de cursos de graduação no interior do estado.

Assim a população interiorana com condições financeiras se deslocava de suas cidades com a finalidade de cursar ensino superior nas capitais do Sul do país. Isto demonstra que o acesso ao ensino superior até a década de 1970 em SC era totalmente elitizado e segregado à capital do estado. 
A expansão e interiorização do Ensino Superior no estado de SC se deu por influência de um modelo econômico industrial dependente que se consolidou como um modelo de universidade diferenciado, que coloca em embate o público e o privado. Na década de 1960 a 1980 havia uma grande demanda de jovens que saiam do Ensino Médio e que desejavam cursar o Ensino Superior, ofertado nas capitais do Sul do país. Assim, se caracteriza o cenário socioeducacional de onde emerge a necessidade pelo ensino superior no interior do estado e que leva lideranças das comunidades regionais do estado a implantarem as ICES, que são instituições públicas de direito privado.

Nos anos 1990 devido à promulgação da LDB 9.394/96, considerada por Trevisol e Trevisol (2009) um divisor de águas nas políticas educacionais brasileiras, pois aferiu um forte impacto para o ensino superior. Articulada com o governo Neoliberal da época, o ensino superior deixava de ser atribuição do Estado, esse passa a compartilhá-lo com a iniciativa privada. Por conotações propriamente mercantilistas, propiciou-se a criação, expansão e interiorização do ensino superior em todo o estado de Santa Catarina, sobretudo na década de 1990.

O processo de expansão do Ensino Superior em Santa Catarina adentra os anos 2000 com maior intensidade, devido a um projeto de sociedade mais includente e com políticas sociais de acesso ao ensino superior, à população mais carente. O Plano Nacional de Educação (PNE) 20012010 (BRASIL, 2001), determinava em uma de suas metas "Prover, até o final da década, a oferta de educação superior para, pelo menos, 30\% da população na faixa etária de 18 a 24 anos" A ideia era tornar o ensino superior acessível também àqueles que nunca tiveram a oportunidade de cursar este nível de ensino, pois no Brasil o ensino superior era reduto de uma elite econômica e com isso diminuir as desigualdades sociais. Ainda a meta sustentava-se na diretriz de "Estabelecer uma política de expansão que diminuía as desigualdades de oferta existentes entre as diferentes regiões do país. (BRASIL, 2001). Com essas diretrizes, houve uma acelerada interiorização e expansão da educação superior no país.

Com a aprovação do PNE 2014/2024, promulgado pela Lei n. 13.005/2014, que estabelece em sua meta 12 , que deve-se,

Elevar a taxa bruta da matrícula na educação superior para cinquenta por cento e a taxa líquida para trinta e três por cento da população de dezoito a vinte e quatro anos, assegurada a qualidade da oferta e expansão para, pelo menos, quarenta por cento das novas matrículas, no segmento público. (BRASIL, 2014).

A interiorização e expansão do ensino superior em SC se deu pela atuação das ICES, porém não se caracteriza juntamente com outras IES enquanto público-estatais, nem privado-particulares, 
criadas pelo poder público municipal, porém de direito privado, tendo como mantenedoras as Fundações Educacionais de Ensino Superior. (TREVISOL; TREVISOL, 2009).

As IES defendem sua característica de comunitárias, pelo fato de terem sido criadas pelo poder municipal - público, não ter um dono - pessoa física e sem fins lucrativos diferentes de outras organizações do mercado. Somente em 2013, a Lei nº 12.881, de 12 de dezembro de 2013 (BRASIL, 2013), oficializa as IES como Instituições de Ensino Superior Comunitárias - ICES. A Lei em questão torna legal a institucionalização de mais um modelo de educação superior no Brasil, distante do modelo público-estatal, das universidades públicas e do modelo representado pelas instituições privadas de educação superior, sendo então o modelo de Universidades Comunitárias - ICES, onde a reconhece enquanto instituições públicas não estatais.

A Lei 12.881/13 institui:

Art. $1^{\circ}$ - As Instituições Comunitárias de Educação Superior são organizações da sociedade civil brasileira que possuem, cumulativamente, as seguintes características:

I - estão constituídas na forma de associação ou fundação, com personalidade jurídica de direito privado, inclusive as instituídas pelo poder público;

II - patrimônio pertencente a entidades da sociedade civil e/ou poder público;

III - sem fins lucrativos, assim entendidas as que observam, cumulativamente, os seguintes requisitos:

a) não distribuem qualquer parcela de seu patrimônio ou de suas rendas, a qualquer título;

b) aplicam integralmente no País os seus recursos na manutenção dos seus objetivos institucionais;

c) mantêm escrituração de suas receitas e despesas em livros revestidos de formalidades capazes de assegurar sua exatidão;

IV - transparência administrativa, nos termos dos arts. $3^{\circ}$ e $4^{\circ}$;

V - destinação do patrimônio, em caso de extinção, a uma instituição pública ou congênere. (BRASIL, 2013).

Assim, tais instituições de Ensino Superior são reconhecidas pelo poder maior como instituições de caráter público não estatal, o que vinha sendo reivindicado pelas ICES. Este novo modelo de IES se diferencia em sua natureza e configuração de outros modelos jurídicos do país. As ICES possuem características do público em seu sentido lato, aquele que concebe o público enquanto espaço social e coletivo construído por outra esfera pública, a esfera pública não estatal. (FRANTZ; SILVA, 2002).

As ICES apresentam como características, o desenvolvimento de atividades sem fins lucrativos; transparência administrativa; austeridade na gestão financeira e a ênfase no desenvolvimento da comunidade local e regional onde estão localizadas, constituindo-se um espaço entre o público estatal e o privado, pois como já dito, nasce pela movimentação de municípios, lideranças e organizações desejosos por um espaço mais amplo e democrático de acesso ao ensino superior. Assim, as ICES possuem características do público enquanto espaço social constituído pela esfera comunitária. 
As ICES representam estas instituições comprometidas com o ensino superior, atuando em parceria com o poder público estatal. Elas representam a ampliação do espaço do Estado, somando-se a este.

As ICES criadas pela iniciativa da sociedade civil e constituídas legalmente sob o regime de fundação de direito privado, agem de acordo com os princípios constitucionais da legalidade, impessoalidade, economicidade, eficiência, moralidade e publicidade. (FRANTZ; SILVA, 2002).

As mantenedoras das ICES não se subordinam aos interesses empresariais, atuando sem visar lucro e nem o distribuem, pois esse é reinvestido em benefício próprio, em estrutura física, capacitação de professores, pró-labore de funcionários técnicos administrativos e corpo docente, pesquisa e extensão junto à comunidade. Atuam por um modelo de gestão democrática e transparente, com a participação de representantes da comunidade interna e externa em seus órgãos deliberativos; seus dirigentes pertencem a própria instituição, onde são eleitos pela comunidade acadêmica e por representantes da comunidade regional; prestam contas à comunidade e ao poder público apresentando forte vínculo com a população e a região, atuando para a promoção do desenvolvimento regional. (SCHMIDT; CAMPIS, 2009).

Em Santa Catarina as ICES compõe um sistema de educação superior criado em 1974, no qual os presidentes das fundações comunitárias criadas por lei municipal e das fundações criada pelo estado constituíram a Associação Catarinense das Fundações Educacionais - ACAFE, entidade essa, sem fins lucrativos. Com a missão de "[...] promover a integração dos esforços de consolidação das instituições de ensino superior por elas mantidas, de executar atividades de suporte técnicooperacional e de representá-las junto aos órgãos dos Governos Estadual e Federal”. (ACAFE, 1974) ${ }^{1}$.

Dentre as Instituições pertencentes ao Sistema Acafe, destacamos a Universidade do Oeste de Santa Catarina - UNOESC, localizada na região oeste do estado, organizada em um modelo multicampi, possuindo campus em cinco cidades da região Oeste, Joaçaba, Videira, Xanxerê, Chapecó e São Miguel do Oeste, e mais cinco unidades nas cidades de: Campos Novos, Capinzal, Maravilha, Pinhalzinho, São José do Cedro e Xaxim.

A Unoesc Xanxerê iniciou suas atividades em 1987 oferecendo o curso de Ciências Contábeis em seguida oferece o curso de Pedagogia. Atualmente oferece dezoito (18) cursos de graduação em todas as áreas do conhecimento, oferecendo ainda cursos de Latu Sensu em diversas áreas e Stricto Sensu na área da saúde animal.

\footnotetext{
${ }^{1}$ http://www.new.acafe.org.br/acafe/acafe/memoria
} 


\section{ESBOÇO TEÓRICO DA EDUCAÇÃO COMO MEIO PARA O DESENVOLVIMENTO SOCIAL}

Para dar início a este texto, queremos aqui nos apropriar da fala de Paulo Freire (1987), onde nos chama a atenção ao processo de socialização e de envolvimento com o outro, mesmo diante de tantas diferenças culturais que na maioria das vezes nos torna desiguais politicamente, socialmente, culturalmente e economicamente. Porém, a sociedade tem aqui nas palavras de Freire, uma grande oportunidade e ao mesmo tempo uma fragilidade que se não buscarmos a prática da alteridade corremos o risco de contribuir para que a humanidade deixe de viver em civilidade, pois temos dificuldades de conviver com o diferente, o que coloca a sociedade no campo da barbárie. Por isso Freire nos diz:

Se alguém não é capaz de sentir-se e saber-se tão homem quanto os outros, é que lhe falta ainda muito que caminhar, para chegar ao lugar de encontro com eles. Neste lugar de encontro, não há ignorantes absolutos, nem sábios absolutos: há homens que, em comunhão, buscam saber mais. (FREIRE, 1987. p.80).

A jornada para se viver em sociedades em que as diferenças culturais não seja um problema é algo emergente, porém está em processo de construção. Há sociedades mais próximas ao que se pode chamar de sociedades includente com seus diferentes, já outras se encontram em estágio bastante precoce. Entendemos que a educação que é entendida como o processo de transmissão de saberes das gerações adultas para as gerações mais novas garante a preservação do legado cultural já existente. A educação é um instrumento que permite a perpetuação da espécie da humanidade (SAVIANI, 2008), garantindo assim a existência da humanidade. A educação é o instrumento criado pelas sociedades para formar e instruir os indivíduos à viver em sociedade.

Há quase uma unanimidade entre os autores de considerar a educação como um processo de desenvolvimento: o ser humano se desenvolve e se transforma continuamente, e a educação pode atuar na configuração da personalidade a partir de determinadas condições internas do indivíduo. (LIBÂNEO, 2010, p.74).

Cabe à sociedade criar espaços de socialização para que haja promoção do conhecimento, iniciando no ambiente privado e se estendendo para o ambiente público com o intuito de inserir o indivíduo à vida em sociedade. O Estado brasileiro por meio de sua lei maior a Constituição federal de 1988, estabelece: “Art. 5ª A educação, direito de todos e dever do estado e da família, será promovida e incentivada com a colaboração da sociedade, visando ao pleno desenvolvimento da pessoa, seu preparo para o exercício da cidadania e sua qualificação para o trabalho". (BRASIL, 1988, p. 15). 
A educação elemento fundante das sociedades, se faz presente na Constituição Federal, promulgada em 1988 como uma garantia social à sociedade. A Constituição estabelece: “Art. 6a . São direitos sociais a educação, a saúde, a alimentação, o trabalho, a moradia, o transporte, o lazer, a segurança, a previdência social, a proteção à maternidade e à infância, a assistência aos desamparados, na forma desta Constituição.” (BRASIL, 1988, p. 20).

Os ambientes institucionalizados de educação como escolas e universidades são responsáveis em explorar e desenvolver as potencialidades do indivíduo para que este se desenvolva intelectualmente e assim possa atuar na sociedade de forma a contribuir com seu desenvolvimento. A educação propiciada em ambientes institucionalizados é compreendida enquanto educação formal, que é "[...] aquela estruturada, organizada, planejada intencionalmente, sistemática. Nesse sentido, a educação escolar convencional é tipicamente formal" (LIBÂNEO, 2010, p.88). Cabe a esta educação formal no ambiente universitário munir o indivíduo de conhecimento científico, cultural e técnico profissionalizante preparando-o para a vida e para o trabalho.

\title{
4 UNIVERSIDADE COMUNITÁRIA: PERSPECTIVA PARA A EXTENSÃO COMUNITÁRIA
}

As Universidades Comunitárias que são frutos dos anseios da sociedade, pertencendo a própria comunidade tem como missão o desenvolvimento da comunidade, no sentido de que o conhecimento produzido nela deve voltar à comunidade para o seu desenvolvimento. Entende-se que a Extensão Comunitária tem papel fundamental neste processo. Porém, é comum identificar a extensão dentro das universidades como algo sem objetivo claro e definido, no entanto, ela é uma das funções do tripé da universidade, realizada por meio de um conjunto de ações dirigidas à sociedade, as quais devem estar indissociavelmente vinculadas ao Ensino e à Pesquisa. Assim,

\begin{abstract}
No caso da extensão o que percebemos é que ela produz conhecimento a partir da experiência e assim tem uma capacidade de narrar sobre o seu fazer. O conhecimento narrativo ele não fecha, ele deixa sempre aberto ao final para a possibilidade de se criar outros finais ou se iniciar outros processos. Assim, a forma de produção da narrativa não pretende ser verdadeira objetivamente, mas ser também subjetiva. Além disto, o que se verifica na extensão é um fazer que sempre pressupõe a presença de um outro que não é somente o aluno ou professor, mas um ouvinte. (CASTRO, 2004. p. 3-4, grifo do autor).
\end{abstract}

Sua finalidade é, sobretudo, a promoção e o desenvolvimento do bem-estar físico, social, ético e cultural, bem como a promoção e a garantia dos valores democráticos de igualdade de direitos, de participação e de respeito à pessoa humana. Ainda segundo o mesmo autor:

Muitas das atividades de extensão universitária serviram, e ainda servem como reveladora da abertura da Universidade para as comunidades. Se analisarmos com cuidado, veremos que 
algumas propostas funcionam como as políticas sociais compensatórias, suficientes para acalmar os conflitos sociais sem criar ou possibilitar a criação de novas possibilidades e saídas para os grupos envolvidos. Porém, existem avanços na reflexão sobre a extensão universitária e os questionamentos feitos através dos anos, trazem para o debate acadêmico a discussão de sua verdadeira função e quais deverão ser suas características. (CASTRO, 2004. p. 4/5).

A extensão se articula em um espaço privilegiado de produção, de acumulação e de disseminação de conhecimentos, desenvolvendo a formação e a capacitação profissional e que na menor das hipóteses, possui um potencial capaz de elaborar políticas públicas, que tenham a cidadania e o cidadão como as suas principais referências. Portanto, a extensão por si só, é um processo considerado interdisciplinar por sua própria natureza.

Sendo assim,

A conquista da interdisciplinaridade entre ensino, pesquisa e extensão representa hoje um dos maiores desafios das universidades brasileiras, e a discussão sobre tal tema assume renovada importância neste momento em que se propõe uma reforma universitária. Enquanto a pesquisa e o ensino têm sido alvo de discussões que originaram elaborados sistemas de avaliação da produção científica e da qualidade dos cursos, a extensão universitária, por outro lado, não recebeu a mesma ênfase, nem sofreu as transformações necessárias em ritmo e intensidade pertinentes para acompanhar a evolução do ensino superior. (JEZINE, 2004, p.3).

Ao pensar a Universidade, identificamos na Extensão, pelo menos três funções: em primeiro lugar a função acadêmica: que fundamenta as bases teórico-metodológicas; a segunda função é social: pois promove a organização social e a construção da cidadania e por fim identificamos uma função articuladora: do saber e do fazer e da universidade com a sociedade.

A nova visão de extensão universitária passa a se constituir parte integrante da dinâmica pedagógica curricular do processo de formação e produção do conhecimento, envolvendo professores e alunos de forma dialógica, promovendo a alteração da estrutura rígida dos cursos para uma flexibilidade curricular que possibilite a formação crítica. (JEZINE, 2004, p.3).

A Universidade Comunitária tem um dever moral com a comunidade em estender o conhecimento produzido internamente para a comunidade, seja em forma de serviços comunitários ou do saber aplicado com o intuito do desenvolvimento da comunidade de forma a garantir o pleno desenvolvimento social, econômico e ambiental, tripé proposto pela Constituição Federal de 1988.

\subsection{A EXTENSÃO COMUNITÁRIA DA UNIVERSIDADE DO OESTE DE SANTA CATARINA} - UNOESC XANXERÊ

A Universidade do Oeste de Santa Catarina como instituição pública, de direito privado, tem como missão: "Promover a formação humana e profissional, por meio do ensino, da pesquisa e da 
extensão, gerando conhecimento para o desenvolvimento regional com sustentabilidade" (PDI/UNOESC, 2018, p. 30-31). Assim, a Unoesc tem por finalidade contribuir com os processos de desenvolvimento, mediante a produção e a difusão do conhecimento e da cultura, por meio do ensino, da pesquisa e da extensão, garantindo, para todas as áreas do conhecimento, atividades profissionais, recursos humanos preparados do ponto de vista tecnológico, científico, político e social, capazes de responder aos desafios e demandas da contemporaneidade. O Fórum Nacional de Extensão (2007) considera a extensão como um ponto essencial para a formação acadêmica, assim:

\begin{abstract}
A Extensão Universitária é o processo educativo, cultural e científico que articula o Ensino e a Pesquisa de forma indissociável e viabiliza a relação transformadora entre Universidade e Sociedade. A Extensão é uma via de mão-dupla, com trânsito assegurado à comunidade acadêmica, que encontrará, na sociedade, a oportunidade de elaboração das práxis de um conhecimento acadêmico. No retorno à Universidade, docentes e discentes trarão um aprendizado que, submetido à reflexão teórica, será acrescido àquele conhecimento. Esse fluxo, que estabelece a troca de saberes sistematizados, acadêmico e popular, terá como consequências a produção do conhecimento resultante do confronto com a realidade brasileira e regional, a democratização do conhecimento acadêmico e a participação efetiva da comunidade na atuação da Universidade. Além de instrumentalizadora deste processo dialético de teoria/prática, a Extensão é um trabalho interdisciplinar que favorece a visão integrada do social". (FOREXT, 2007, p. 05).
\end{abstract}

A Unoesc Xanxerê tem como proposta para a extensão comunitária, construir competências e habilidades profissionais para ir além do conhecimento teórico da sala de aula, estendendo-o para a comunidade, por meio da Extensão Comunitária subsidiada pela própria Universidade.

O Programa de Extensão Comunitária, foi organizado para atender os acadêmicos com bolsas de estudo e, em contrapartida, o acadêmico contemplado, deverá prestar trabalho comunitário de cunho educativo, vinculado ao seu curso de graduação, devendo participar de projetos sociais, no mínimo com 20 horas semestrais, apresentando ao final o relatório de participação, sob pena de não mais poder participar do programa de Bolsas de Estudo, além da necessidade de devolução dos recursos, devidamente corrigidos.

Diante disso, enfatiza-se que o estudante em contato com a coordenação de seu curso recebe orientações acerca das atividades a serem desenvolvidas. O curso de graduação é responsável pela organização das atividades a serem desenvolvidas, iniciando pela formação dos acadêmicos, discussão dos temas com os bolsistas, preparação do material, capacitando-os para realizar as tarefas de forma organizada, comprometida, competente na execução das atividades. Este programa visa estimular os bolsistas a envolverem-se no contexto social em que estão inseridos, envolvendo anualmente cerca de 750 acadêmicos atuando junto à comunidade local e regional.

A extensão comunitária está sendo além de instrumentalizadora no processo dialético, também um trabalho interdisciplinar. Com esse pensamento é necessário destacar que o trabalho dos 
Projetos de Extensão Comunitária, acontece com a colaboração de todos, envolvendo o coordenador do Curso de graduação e o Coordenador do Projeto de Extensão, estando preparados para mudanças e motivando os acadêmicos bolsistas envolvidos no processo, desenvolvendo a compreensão crítica e política, bem como a percepção e sensibilidade para identificar as necessidades da comunidade, mantendo-se sempre atualizados, buscando fontes de inovação e refletindo sobre o contexto social em que estão inseridos.

Desta forma necessitamos fortalecer os objetivos do programa, bem como da própria extensão, dentre eles podemos listar: identificar a extensão comunitária como processo acadêmico definido e efetivado em função das exigências da realidade, voltadas a formação do acadêmico, na qualificação do profissional e na sua relação com a sociedade; priorizar práticas voltadas para o atendimento de necessidades sociais; criar condições para a participação da universidade na elaboração das políticas públicas; possibilitar novos meios de produção, inovação e transferência de conhecimentos e ampliação do acesso ao saber; atender as exigências do artigo 170 da Constituição do Estado de Santa Catarina, no que tange a bolsa de estudos dos acadêmicos da Unoesc Xanxerê.

A função essencial da universidade se efetiva, assim, por um processo de aprendizagem que se faz por meio do encaminhamento das finalidades do ato educativo, que segundo a lei de Diretrizes e Bases - LDB -, configura-se pelo ato educativo, pela capacitação para o trabalho e pelo exercício da cidadania. Mas realiza-se, também, pela inserção na realidade social, pelo envolvimento com os projetos comunitários e pela implementação de propostas que contribuam para a formação social (FOREXT, 2007, p 14).

A Unoesc entende a extensão como um processo educativo e científico, produzindo conhecimento que viabiliza a relação transformadora entre a instituição e a comunidade, alicerçada na troca de saberes e que deve servir como instrumento para alcançar seus objetivos, não somente pedagógicos, mas também sociais, políticos e culturais.

Em qualquer espaço, em que se reúnem atores dos diferentes contextos, a concepção do objeto apresenta-se de forma diferenciada e na tentativa de dar unidade aos conceitos, contribui para o desenvolvimento social, político e cultural das pessoas que estão no seu entorno, promovendo o desenvolvimento local e regional de forma sustentável. Assim, o processo educativo, cultural e científico que se articula no ensino, na pesquisa e na extensão de forma indissociável, viabiliza a relação política entre a universidade e a sociedade, concepção essa que se torna um instrumento viabilizador da função social da universidade e a extensão tem uma grande responsabilidade neste processo, sendo uma ferramenta necessária e útil para tornar os produtos da universidade mais próximos da sociedade, sendo este o papel histórico da extensão: aproximar a universidade da sociedade. 
Desta forma, a Extensão Comunitária é desenvolvida atendendo as demandas da academia e da comunidade externa, que apresenta uma diversidade conceitual, teórica e prática que interfere expressivamente no pensar e no fazer no interior da própria Instituição, nas interfaces entre o saber produzido com a cultura local e desta com a cultura universitária.

Dentro das diversas atribuições está o ato de acompanhar o trabalho, sendo responsável pelo elo entre a Unoesc e a comunidade. A questão do relacionamento entre os envolvidos é um fator crucial para uma gestão democrática do espaço acadêmico e social, e para que isso aconteça, as estratégias são formuladas no coletivo, para garantir o foco do trabalho comunitário com visão educativa, conforme estabelecido na legislação vigente, considerando o artigo 170 da Constituição do Estado de Santa Catarina. Kuenzer, (2004) é feliz quando nos apresenta a reflexão sobre o currículo, dizendo que para a formação de um bom profissional, precisamos partir do princípio de que muitos dos seus conhecimentos partem da prática do próprio acadêmico trabalhador, com base na sua experiência profissional, fortalecendo assim as discussões em sala de aula. Já se este currículo, não atende aos anseios da comunidade acadêmica, pouco poderá ser feito, assim,

[...] a partir de um currículo que se iniciava com uma base de formação geral, seguida de formação especializada para um campo profissional e às vezes, de estágio ao final do curso, busca-se articular os conhecimentos teóricos aos necessários à prática do trabalho. (KUENZER, 2004, p. 2).

Diante das situações que se apresentam no cenário atual, faz-se necessário valorizar e provocar os envolvidos, acadêmicos e comunidade, para conscientizá-los no sentido da importância de se fazerem presentes na comunidade juntamente com a Universidade estendendo o saber para fora de seus muros, fazendo esse chegar até a comunidade, além de cumprir com o objetivo que é de contribuir com o desenvolvimento local. Desta forma é possível fortalecer os laços de solidariedade com a comunidade. Esta aproximação entre Universidade e comunidade é reconhecida como,

[...] a ampliação das relações da universidade com a sociedade e seus problemas mais emergentes, propiciando um maior envolvimento dos alunos e uma proximidade com as necessidades da comunidade. Permite que os mesmos ampliem e apliquem seus conhecimentos, que participem de uma determinada realidade compartilhando crenças, valores, motivações, pontos de vista, sentimentos, interesses e percepções e, finalmente, a realização deste trabalho se transforme em uma lição de cidadania. (BIER, 2005, p. 60).

Com grande frequência, identificamos discursos que apresentam como processo de aprendizagem, apenas o ensino, apresentado em sala de aula, ou vinculando a pesquisa como um processo de construção e produção do conhecimento, enquanto a ideia da extensão como processo formativo acaba ficando em segundo plano. Assim, como diz Freire (1991) para fortalecer o processo de apreensão do conhecimento, faz-se necessário considerar o conhecimento já adquirido pelo 
próprio educando/acadêmico. Com a oportunidade da experiência com a extensão, fortalecerá seu perfil e conhecimento profissional, com base no processo de retroalimentação vinculado a vida cotidiana dos envolvidos. A relação entre a teoria e a prática se faz constante na extensão comunitária, mediado por um processo pedagógico em que o acadêmico exerce a função de conduzir o conhecimento teórico para uma determinada realidade, produzindo-se assim na comunidade o saber técnico para o saber fazer.

Neste momento o acadêmico vê o ensino e a pesquisa, transformando-se em um processo de socialização, pois fortalece a experiência da relação entre o conteúdo específico onde o mesmo tem desenvolvido tanto no ensino como pela própria pesquisa articulados com o ambiente prático. Dessa forma, percebemos a necessidade de dar resposta aos sujeitos, bem como para a sociedade em geral sobre os estudos e descobertas produzidas pela universidade e pelos grandes centros de pesquisa. Este papel deve ser fortalecido dentro e fora da Universidade, porém, a decisão política de investimento, deve ser em primeiro lugar da própria Instituição de ensino, organização esta, responsável pela profissionalização do seu entorno.

Ao se investir de poder político, a população e, principalmente, os usuários vivenciam um interessante processo pedagógico de aprendizado do exercício da cidadania, o que leva ao estabelecimento de relação da população com o governo, a partir de um patamar diferenciado, como atores sociais e não mais como atores passivos e alheios. (COSTA; NORONHA, 2003, p. 362).

Diante dos desafios da universalização do saber, tanto dentro da universidade como fora dela, torna-se importante analisar as concepções políticas e ideológicas implícitas e explícitas dentro dos marcos teóricos da Universidade, como também, sua concepção de extensão universitária, identificando as implicações sociais que tais concepções podem trazer para a prática comunitária a partir do currículo de cada curso de graduação, no sentido de prospectar a formação, capazes e responsáveis pelo desenvolvimento da sociedade em que nossa academia está inserido. O desafio imposto às universidades brasileiras hoje por consequência à extensão universitária no mundo cada vez mais internacionalizado globalizado, onde nos deparamos com as fronteiras políticas, sociais e principalmente econômicas e culturais cada vez mais flexibilizadas, se faz emergente, portanto, percebermos o elemento articulador da teoria-prática, estreitando as relações entre a universidadecomunidade, demonstrando a reciprocidade entre ambas, integrando o pensar, o fazer e o viver, rompendo a dimensão dicotômica e fragmentada presente no fazer clássico universitário.

A política da Universidade do Oeste de Santa Catarina acompanha o pensamento de Buarque, (1986), no que tange o fazer da própria universidade na produção do conhecimento e principalmente no processo de socialização de resultados tanto da pesquisa como do ensino, sendo que, 
[...] a política da universidade deve combinar o máximo de qualidade acadêmica com o máximo de compromisso social... O que caracterizará o produto, portanto, é a sua qualidade acadêmica, sua condição de elite, mas o que caracterizará seu uso e seu compromisso amplo - a sua condição antielitista. (BUARQUE, 1986, p.22).

A Universidade, desta forma busca cooperar com os bolsistas, contribuindo para sua formação acadêmica, cidadã, humana e ética, criando um espaço de sociabilidade com as diferenças culturais existentes no contexto da comunidade, que como já mencionado no início deste trabalho é um dos desafios da sociedade na contemporaneidade. Proporcionar o contato dos acadêmicos com uma realidade que muitas vezes não é a conhecida por ele em seu cotidiano tende a causar estranheza/espanto que deve ser superada quando a ação acadêmica dentro do contexto da extensão for conduzida com empatia e ética seja pelos profissionais que orientam a extensão comunitária, seja pela postura humana e ética assumida pelos acadêmicos da Unoesc.

\section{CONSIDERAÇÕES FINAIS}

O Programa de Extensão Comunitária visa contribuir social e culturalmente para o desenvolvimento de um processo participativo, possibilitando o envolvimento com a prática profissional, na interface com o ensino e pesquisa, respondendo cientificamente às demandas suscitadas pela comunidade. Assim, a formação do acadêmico vai além da sala de aula, do ensino e da pesquisa, com experiências sociais, desenvolvendo atividades de extensão junto à comunidade. $\mathrm{O}$ conhecimento apreendido na universidade tem um dever ético para com a comunidade, sendo que este deve ser estendido à comunidade para seu desenvolvimento. Isso ocorre não somente com a profissionalização do acadêmico, mas também durante sua caminhada de formação que em seu decorrer tem o dever de apresentar aos acadêmicos múltiplas realidades, para então esse tomar consciência sobre a diversidade social, cultural, econômica e política ainda durante sua formação e com isso ocorrer o despertar da consciência crítica sobre a realidade. Como nos diz Freire,

[...] o homem ao aproximar-se da realidade faz simplesmente a experiência da realidade na qual ele está e procura. Esta tomada de consciência não é ainda a conscientização, porque esta consiste no desenvolvimento crítico da tomada de consciência. A conscientização implica, pois, que ultrapassemos a esfera espontânea de apreensão da realidade, para chegarmos a uma esfera crítica na qual a realidade se dá como objeto cognoscível e na qual o homem assume uma posição epistemológica. (FREIRE, 1980, p. 26)

O programa Extensão Comunitária promovido pela Unoesc Xanxerê resultou em um grande envolvimento de professores e acadêmicos. Por se tratar de uma iniciativa inovadora, os resultados apresentados estão viabilizando novos projetos para que cada ano, mais pessoas da comunidade sejam beneficiadas, fazendo com que os envolvidos no programa de Extensão Comunitária tornem-se 
profissionais melhores qualificados, com experiência em lidar com situações diversas, colaborando com os desafios e demandas da sociedade atual, demonstrando capacidade de conhecimento, doação, respeito ao próximo, criticidade e conscientes do seu papel na sociedade contemporânea.

Assim, conforme Freire, podemos concluir que, [...] a conscientização implica, pois, que ultrapassemos a esfera espontânea da realidade, para chegarmos a uma esfera crítica na qual a realidade se dá como objeto cognoscível e na qual o homem assume uma posição epistemológica. (FREIRE, 1980, p. 26).

O papel da universidade no campo da extensão comunitária é uma tarefa nada fácil, porém, só poderá se firmar como práxis educativa, quando todos os atores envolvidos sejam eles professores, alunos, pessoal técnico-administrativo e gestores, assumem o compromisso com a transformação da realidade social.

A experiência aqui apresentada é resultado dos grandes projetos de Extensão Comunitária e do desejo dos mesmos em estreitar relações com a comunidade e a satisfação em contribuir com grupos sociais. Identificamos também uma grande aproximação da Universidade com a comunidade, experiência esta, que em outros momentos poderia ser considerada extremamente distante em função da sua condição política, social e financeira.

\section{REFERÊNCIAS}

BIER, Clerilei A. Universidade: função e responsabilidade social. In: IV FÓRUM DE EXTENSÃO UNIVERSITÁRIA DA ACAFE. A extensão universitária: fator de ampliação da ação comunitária e pública. Chapecó: Argos, 2005.

BRASIL. Constituição (1988). Constituição da República Federativa do Brasil. Brasília: Senado Federal, Subsecretaria de Edições Técnicas, 2010.

BRASIL. Constituição. República Federativa do Brasil de 1988. Brasília, DF: Senado Federal, 1988.

BRASIL. Lei n. 10.172, de 9 de janeiro de 2001.

http://www.planalto.gov.br/ccivil_03/leis/leis_2001/110172.htm Acesso em 06 de setembro de novembro de 2020.

BRASIL. Lei no 12.881, de 12 de novembro de 2013. Dispõe sobre a definição, qualificação, prerrogativas e finalidades das Instituições Comunitárias de Educação Superior - ICES, disciplina o Termo de Parceria e dá outras providências. Diário Oficial da União. Brasília, DF, 13 nov. 2013a. Disponível em: http://www.planalto.gov.br/ccivil_03/_ato2011-2014/2013/lei/112881.htm Acesso em 06 de novembro de 2020. 
BRASIL. Plano Nacional de Educação 2014-2024. Lei. n. 13.005/2014. Disponível em: http://www.planalto.gov.br/ccivil_03/_ato2011-2014/2014/lei/113005.htm Acesso em 06 de novembro de 2020.

BUARQUE, C. Uma ideia de Universidade. Brasília: Editora Universidade de Brasília, 1986.

CASTRO, Luciana M. Cerqueira. A Universidade, a extensão universitária e a produção de conhecimentos emancipadores. In: 27 ${ }^{\mathrm{a}}$ Reunião Anual da ANPED - Sociedade, Democracia e Educação. Caxambu, Minas Gerais, 2004, Disponível em: https://anped.org.br/sites/default/files/t1111.pdf acesso em janeiro de 2014.

COSTA, A. M.; NORONHA, J. C. Controle Social na Saúde: construindo a Gestão Participativa. Revista Saúde em Debate. V.27, n65, 358-363, set/ dez.2003.

FOREXT - FÓRUM NACIONAL DE EXTENSÃO E AÇÃO COMUNITÁRIA DAS UNIVERSIDADES E INSTITUIÇÕES DE ENSINO SUPERIOR COMUNITÁRIAS, 6., 2007, Campinas, São Paulo. Anais... Unicamp, 2007.

FRANTZ, Walter; SILVA, Enio da. As funções sociais da universidade: o papel da extensão e a questão das comunitárias. Ijuí: Editora Unijuí, 2002.

FREIRE, Paulo. Conscientização: teoria e prática da libertação. São Paulo: Ed Moraes, 1980.

FREIRE, Paulo. Extensão ou Comunicação? Rio de Janeiro: Paz e Terra, 1991.

FREIRE, Paulo. Pedagogia do oprimido. 27. ed. Rio de Janeiro: Paz e Terra, 1987.

JEZINE, Edineide. As Práticas Curriculares e a Extensão Universitária. In: CONGRESSO BRASILEIRO DE EXTENSÃO UNIVERSITÁRIA, 2. Anais do Evento. Belo Horizonte. Disponível em: <http://www.ufmg.br/congrext/ Gestão/Gestao12.pdf> Acesso em: 12 julho de 2013.

KUENZER, Acácia Zeneida. A Universidade e as mudanças no mundo do trabalho: a proposta neoliberal. Material de apoio para o Plano de Desenvolvimento Institucional. Chapecó: Argos, 2004.

LIBÂNEO, José Carlos. Pedagogia e pedagogos, para quê? São Paulo: Cortez, 2010.

LÜCKMANN, Luiz Carlos. O modelo comunitário de Educação Superior. In: ALMEIDA, Maria de Lourdes pinto de; CATANI, Afrânio. (Org.) Educação Superior Iberoamericana: uma análise para além das perspectivas mercadológicas da produção de conhecimento. Ciudade Autônoma de Buenos Aires: CLACSO, 2015.

SAVIANI, Dermeval. A pedagogia no Brasil: história e teoria: São Paulo: Autores Associados, 2008.

SCHMIDT, João Pedro; CAMPIS, Luiz Augusto Costa. As instituições comunitárias e o novo marco jurídico do público-não-estatal. In: SCHMDT, João Pedro (Org.). Instituições comunitárias:

instituições públicas não-estatais. Santa Cruz, RS; Edunisc, 2009.

TREVISOL, Joviles Vitório; TREVISOL, Maria Teresa Ceron. Políticas e dinâmicas do ensino superior em Santa Catarina: análise dos indicadores do Inep (1991-2004). In: Congresso Nacional de Educação, 9., 2009, Paraná. Anais. Curitiba: PUC/PR, 2009. 